\section{${ }^{1}$ Национальный медицинский \\ исследовательский центр \\ онкологии \\ им. Н.Н. Блохина Минздрава РФ (Москва, Россия)}

${ }^{2}$ Первый Московский государственный медицинский университет ип. И.М. Сеченова Минздрава РФ (Сеченовский Университет) (Москва, Россия)

ИССЛЕДОВАНИЕ 2 ФАЗЫ

ПО ИЗУЧЕНИЮ ВНУТРИБРЮШИННОЙ
ХИМИОТЕРАПИИ У БОЛЬНЫХ
РАСПРОСТРАНЕННЫМ
РАКОМ ЯИЧНИКОВ

А.С. Тюляндина ${ }^{1}$, В.М. Нечушкина ${ }^{1}$, Л.В. Черкес ${ }^{1}$, К.Ю. Морхов $^{1}$, А.А. Румянцев ${ }^{1}$, И.А. Покатаев ${ }^{1}$, Е.В. Глазкова ${ }^{1}$, Э.Р. Виршке ${ }^{1}$, Д.Ю. Францев ${ }^{1}$, К.И. Жорданиа ${ }^{1}$ Ю.В. Буйденок ${ }^{1}$, Р.К. Валиев ${ }^{1}$, А.В. Петровский ${ }^{1,2}$, Ю.С. Сергеев ${ }^{2}$, И.В. Паниченко ${ }^{1}$, А.А. Буланов ${ }^{1}$, М.Б. Стенина ${ }^{1}$, С.А. Тюляндин ${ }^{1}$

\title{
INTRAPERITONEAL CHEMOTHERAPY IN PATIENTS WITH ADVANCED OVARIAN CANCER: PHASE 2 INSTITUTIONAL STUDY
}

\section{А.С. Тюляндина ${ }^{1}$} Доктор медищинских наук, стариий научный сотрудник, отделение клинической фармакологии и химиотерапии, НМИЦ онкологии ил. Н.Н. Блохина Минздрава России, 115478, Москва, Каширское шоссе, 23. E-mail: atjulandina@mail.ru.

В.М. Нечуикина Доктор медицинских наук, профессор, ведущий научный сотрудник отделение гинекологии.

Л.В. Черкес ${ }^{1}$ Кандидат медицинский наук, ведуший научный сотрудник, әндоскопическое отделение.

К.Ю. Морхов Кандидат медицинских наук стариий научный сотрудник, отделение гинекологии.

A.А. Румянцев ${ }^{1}$ Врач-онколог,

отделение клинической фармакологии и химиотерапии.

И.A. Покатаев ${ }^{1}$ Кандидат медицинских наук, научный сотрудник, отделение клинической фармакологии и химиотерапии.

\section{E.В. Глазкова} Аспирант отделение клинической фармакологии и химиотерапии.
Э.P. Вирике ${ }^{1}$ Доктор медицински наук, руководитель лаборатории интервенционной радиологии.

Д.Ю. Францев ${ }^{1}$ Аспирант, отделение рентгендиагностическое.

К.И. Жорданиа ${ }^{1}$ Доктормедицинских наук, профессор, ведущий научный сотрудник, отделение онкогинекологии.

Ю.В. Буйденок ${ }^{1}$ Доктор медицинских наук, ведущий научный сотрудник, лаборатория интервенщионной радиологии.

P.К. Валиев ${ }^{1}$ Кандидат медицинских наук, руководитель отделения радиохирургии.

А.В. Петровский $\check{\check{1}}^{1,2}$ Кандидат медицинских наук, заместитель директора по развитию онкологической помощи в регионах, НМИЦ онкологии

им. Н.Н. Блохина Минздрава России; дочент кафедры онкологии, Институт Клинической Медищины, Первый МГму

им. И.М. Сеченова Минздрава России (Сеченовский Университет), 119146, Москва,

Большая Пироговская ул., 19с1. E-mail: alexpetrovsky@botmail.com. 
Ю.C. Сергеев ${ }^{2}$

Кандидат медицинких наук, доцент кафедры онкологии.

И.В. Паниченко ${ }^{1}$ Доктор медицинских наук, ведущий научный сотрудник, отделение радиохирургии.

A.А. Буланов ${ }^{1}$ Доктор медицинских наук, стариий научный сотрудник, отделение клинической фармакологии и химиотерапии.

М.Б. Стенина ${ }^{1}$

Доктор медицинских наук, ведущий научный сотрудник, отделение клинической фармакологии и химиотерапии.

С.А. Тюляндин ${ }^{1}$ Доктор медицинский наук, профессор, руководитель отделения клинической фармакологии и химиотерапии.

A.S. Tyulyandina ${ }^{1}$ Doctor of Medicine, Senior Researcher, Department of Clinical Pharmacology and Chemotherapy, N.N. Blokhin Russian Cancer Research Centre, 115478, Moscow, Kashirskoe shosse, 23. E-mail: atjulandina@mail.ru.

V.M. Nechushkina ${ }^{1}$ Doctor of Medicine, Professor, Senior Researcher, Department of Oncogynecology.

L.V. Cherkes ${ }^{1}$ Candidate of Medicine, Senior Researcher, Department of Endoscopy.

K.Y. Morkhov ${ }^{1}$ Candidate of Medicine, Professor, Senior Researcher, Department of Oncogynecology.

\section{A.A. Rumyantsev ${ }^{1}$} Oncologist,

Department of Clinical Pharmacology and Chemotherapy.

\section{I.A. Pokataev ${ }^{1}$}

Candidate of Medicine, Researcher, Department of Clinical Pharmacology and Chemotherapy.

E.V. Glazkova ${ }^{1}$ Postgraduate Student, Department of Clinical Pharmacology and Chemotherapy.
E.R. Virshke ${ }^{1}$

Doctor of Medicine,

Head of Department of Intervention Radiology.

D.Y. Frantsev ${ }^{1}$

Postgraduate Student,

Department of Intervention Radiology.

K.I. Zbordania ${ }^{1}$

Doctor of Medicine, Professor,

Senior Researcher,

Department of Oncogynecology.

Y.V. Bujdenok ${ }^{1}$

Doctor of Medicine, Senior Researcher, Department of Intervention Radiology.

R.K. Valiev ${ }^{1}$

Candidate of Medicine,

Head of Department of Radiosurgery.

A.V. Petrovsky ${ }^{1,2}$ Candidate of Medicine, Deputy Director of Regional Development, N.N. Blokbin Russian Cancer Research Center; Associate Professor,

Oncology Institute of Clinical Medicine, I.M. Sechenov First Moscow State Medical University (Sechenov University), 119146, Moscow, Bolshaya Pirogovskaya ul., 19c1.

E-mail: alexpetrovsky@botmail.com.

Y.S. Sergeev ${ }^{2}$ Candidate of Medicine, Associate Professor, Department of Oncology.

I.V. Panichenko ${ }^{1}$

Doctor of Medicine, Senior Researcher, Department of Radiosurgery.

A.A. Bulanov ${ }^{1}$ Doctor of Medicine, Senior Researcher, Department of Clinical Pharmacology and Chemotherapy.

M.B. Stenina ${ }^{1}$ Doctor of Medicine, Senior Researcher, Department of Clinical Pharmacology and Chemotherapy.

S.A. Tyulyandin ${ }^{1}$

Doctor of Medicine, Professor,

Head of Department of Clinical Pharmacology and Chemotherapy.

Введение: внутрибрюшинная (в/б) химиотерапия у больных раком яичников (РЯ) в 1 линии лечения показала позитивные результаты в трех рандомизированных исследованиях. Однако данный метод до сих пор не является рутинным в клинической практике.

Материалы и методы: нами было проведено исследование 2 фазы по изучению 1 линии химиотерапии с в/б введениями, в которое включались больные РЯ с Ic - IV стадиями после первичной оптимальной циторедукции. Интраперитонеальные порт-системы устанавливались интраоперационно или лапароскопическим методом. Пациенты получали режим химиотерапии: паклитаксел 135 мг/м² в/в в 1-й день, цисплатин 75 мг/м² в/б во 2-й день и паклитаксел 60 мг/м² в/б в 8-й день, всего 6 курсов. 
Результаты: с 2009 по 2017 год в исследование было включено 64 пациентки. Медиана времени без прогрессирования (ВБП) составила 38,6 мес., медиана продолжительности жизни (Пж) 79,4 мес. Пациентки получили все запланированное лечение в 79,7\% случаев. При ретроспективном сравнении с аналогичной группой больных, получавших стандартную внутривенную (в/в) химиотерапию с 2007-2017 год, не было получено различий как в медиане ВБП, так и ПЖ. Сравнительный анализ больных с полной циторедукцией продемонстрировал достоверное увеличение ВБП на 11,7 мес. при использовании в/6 химиотерапии, чем стандартного в/в введения: 38,6 мес. для в/б и 26,9 мес. для в/в химиотерапии, p=0,05; ОР 0,53 (95\% ДИ 0,27-0,96). Та же тенденция наблюдалась для больных с III-IV стадиями РЯ: медиана ВБП для в/б группы составила 38,6 мес. и 22,9 мес. для в/в, p=0,05; ОР 0,60 (95\% ДИ 0,36-0,98).

Выводы: изученный режим в/б химиотерапии переносим подавляющим большинством больных. В/б химиотерапия в рамках 1 линии лечения может быть рекомендована больным с минимальной резидуальной опухолью после первичной циторедукции.

Ключевые слова:рак яичников, внутрибрюшинная химиотерапия, внутривенная химиотерапия, оптимальная циторедукция, цисплатин, паклитаксел.

Background: despite the fact that intraperitoneal (IP) chemotherapy in patients (pts) with ovarian cancer (OC) in 1 line of treatment showed positive results in three randomized studies, this method is still not routine in clinical practice.

Materials and methods: phase 2 study of the first line IP chemotherapy in pts with OC stage Ic - IV after primary optimal debulking was conducted. IP ports were implanted intraoperatively or by laparoscopic approach. Pts were administered every 3 weeks intravenous (IV) paclitaxel $135 \mathrm{mg} / \mathrm{m}^{2}$ day 1, IP cisplatin $75 \mathrm{mg} / \mathrm{m}^{2}$ day 2 and IP paclitaxel $60 \mathrm{mg} /$ $\mathrm{m}^{2}$ day 8 for 6 cycles.

Results: from 2009 to 201764 pts were included in the study. Progression free survival (PFS) was 38,6 months, overall survival (OS) was 79,4 months. In 79,7\% of cases, the pts received all planned treatment. In retrospective comparison with similar group of pts who received standard IV chemotherapy in 2007-2017 no any significant difference were found in PFS and OS. A comparative analysis of pts with complete cytoreduction demonstrated significant increase in PFS of 11,7 months after IP chemotherapy than standard IV administration: 38,8 months for IP and 26,9 months for IV (HR 0,53; $95 \%$ CI $0,27-0,96 ; \mathrm{p}=0,05)$. The same trend was observed for pts with stage III-IV: PFS for IP group was 38,6 months and for IV - 22,9 months (HR 0,$60 ; 95 \%$ CI 0,36-0,98; $\mathrm{p}=0,05$ ).

Conclusion: studied IP regimen of chemotherapy is tolerable for majority of pts. The use of IP chemotherapy in first line OC may be an option in pts with minimal residual tumor after primary cytoreduction.

Keywords: ovarian cancer, intraperitoneal chemotherapy, intravenous chemotherapy, optimal cytoreduction, cisplatin, paclitaxel.

\section{Введение}

$\mathrm{P}$ ак яичников (РЯ) является серьезной проблемой, решением которой занимается совместно команда специалистов, включающая хирургов и химиотерапевтов. Несмотря на то, что опухоль является химиочувствительной и наиболее эффективный режим терапии первой линии определен более 20 лет назад, прогрессирование возникает у преобладающего большинства больных с распространенным РЯ [1]. В связи с чем изменение методики введения цитостатиков (паклитаксела и препаратов платины) стало одним из интенсивно изучаемых направлений за последние десятилетия.

Изначально в/б введение цитостатиков рассматривалась как паллиативная процедура и своей целью преследовала уменьшение или полное прекращение накопления жидкости в брюшной и плевральных полостях у больных разными подтипами злокачественных опухолей. В 80-х годах XX века стало активно обсуждаться систематическое введение в брюшную полость цитостатиков во время первой линии химиотерапии совместно с в/в введениями у больных РЯ [2]. Причин для такого подхода оказалось несколько. Во-первых, основной процесс метастазирования РЯ и последующего прогрессирования в большинстве случаев реализуется по брюшине. Во-вторых, введение цитостатических агентов в брюшную полость приводит к увеличению концентрации активного вещества, при этом, не усиливая частоту развития системной токсичности. Помимо увеличения концентрации возрастает экспозиция препарата при введении непосредственно в брюшную полость в сравнении со стандартным в/в введением. Например, воздействие цисплатина в брюшной полости, как наиболее изученного цитостатика, увеличивается в 10-20 раз по сравнению со стандартным системным введением [3].

Изучение в/б химиотерапии при РЯ, как систематического введения цитостатиков в брюшную полость стало активно развиваться с начала 90-х годов. До настоящего времени опубликовано 9 рандомизированных клинических исследований по анализу интраперитонеальной химиотерапии у больных РЯ в первой линии лечения. Однако только 4 из них, опубликованные группой GOG, включали большое число больных и относятся к исторически значимым. В трех крупных исследованиях (GOG104, GOG114 и GOG172) было получено достоверное увеличение как медианы ВБП, так и медианы ПЖ. Полученные данные не вызывали никаких сомнений в преимуществе в/б химиотерапии в сравнении со стандартным системным введением. Трудности с внедрением метода заключались в высокой 
частоте осложнений, связанных с в/б порт-системами, что не позволяло большинству больных получить все лечение с интраперитонеальными введениями. Поэтому в 2009 году было инициировано исследование GOG252 по изучению в/б ХT с редукцией дозы цисплатина и бевацизумабом, на который большинство экспертов возлагали болышие надежды. В исследовании было показано, что еженедельный в/в режим с бевацизумабом, в/б карбоплатин или в/б цисплатин с бевацизумабом были одинаково эффективными как у всех больных, так и в подгруппах с остаточной опухолью до 1 см, так и после полной циторедукции. Несмотря на то, что данные GOG252 внесли некоторые сомнения в эффективность в/б химиотерапии, авторы предлагают не исключать данный метод лечения из рекомендаций и предлагают использовать в/б ХТ у больных с нарушением гомологичной рекомбинации (HRD) после полной циторедукции по схеме, изученной в исследовании GOG172, где доза цисплатина составила 100 мг/м² и не использовать бевацизумаб.

В связи с полученными разрозненными данными публикация собственного опыта отдельных клиник может позволить оценить эффективность в/б химиотерапии у больных РЯ в рутинной практике.

\section{Материалы и методы}

Нами проведено проспективное исследование II фазы по оценке эффективности и токсичности в/б химиотерапии у больных распространенным РЯ. Критериями включения в исследование являлись следующие: больные с гистологически доказанным PЯ/ маточной трубы/ брюшины Ic-IV стадий после полной или оптимальной (остаточная опухоль $\leq 1$ см в диаметре) циторедукции, отсутствие остаточной опухоли в висцеральных органах, в удовлетворительном общем статусе (ECOG 0-2) при нормальной функции внутренних систем.

Пациенткам имплантировалась в/б порт-система интраоперационно или лапароскопическим доступом [8]. В последующем пациенты получали разработанный нами режим химиотерапии с включением паклитаксела 135 мг/м² в/в в 1-й день, цисплатина 75 мг $/ \mathrm{M}^{2}$ в /б во 2-й день (при невозможности введения цисплатин заменялся на карбоплатин AUC6) и паклитаксела 60 мг/м² в/б на 8-й день. В/б химиотерапия начиналась через 3 недели после хирургического вмешательства. В дни введения паклитаксела проводилась стандартная премедикация дексаметазоном, а в дни в/б введений цисплатина - гидратация физиологическим раствором (в/в вводилось 1500 мл жидкости). При в/б введении в брюшную полость препарат растворялся в 2000 мл жидкости температурой $37^{\circ} \mathrm{C}$, что должно было обеспечить равномерное распределение цитостатического агента по всей поверхности брюшины, уменьшить ее раздражение и снизить выраженность болевого синдрома. Интервал между циклами составлял 3 недели, считая от первого дня. Всего планировалось проведение 6 курсов химиотерапии. При развитии токсичности 3-4 ст. к 8-му дню очередного курса химиотерапии введение в этот день пропускалось. При сохранении или появлении токсичности (нефротоксичности, полинейропатии) к началу очередного курса химиотерапии мы придерживались общепринятой схемы редукции доз.

Первичной конечной точкой в исследовании являлась медиана ВБП. Статистическая гипотеза рассчитывалась исходя из данных отделения клинической фармакологии. Однолетнее ВБП составляет 60\%, для улучшения данного показателя до 85\% необходимо включить в исследование 60 пациенток, при условии значения $\alpha=0,05$ и $\beta=0,8$.

В дальнейшем мы провели анализ по сравнению эффективности в/б химиотерапии 1-й линии с историческим контролем, отобрав для этого пациенток с аналогичными критериями включения, получавших в 1 линии химиотерапии паклитаксел и препараты платины в/в каждые 3 недели за период с 2007-2016 год.

На последующем этапе нами был проведен дополнительный сравнительный анализ эффективности в/б химиотерапии только для больных с микроскопическими проявлениями остаточной опухоли после полной циторедуктивной операции, поскольку мы посчитали, что может возникнуть погрешность в оценке хирургической бригадой остаточных очагов диаметром до 1 см. При условии увеличения 1-летней ВБП с 80 до 95\% при сроках наблюдения 2 года и набора в течение 5 лет при $\alpha=0,05$ и $\beta=0,8$ необходимо было включить в каждую группу по 32 пациентки. С учетом возможного исключения больных из исследования в связи с несоответствием критериям включения дополнительно добавлено по 10\%. Таким образом, необходимо было набрать по 35 больных в каждой группе.

\section{Результаты}

В исследование были включены больные, проходившие лечение в отделении клинической фармакологии и химиотерапии с 2009-2017 год. В/б порт был установлен 64 пациенткам, из них в 21 (32,8\%) случае порт система установлена лапароскопически. Характеристика больных представлена в таблице 1.

Все запланированное лечение с в/б введениями не закончили 13 (20,3\%) пациенток. Наиболее частой причиной оказалась токсичность, связанная с портсистемой $(9,3 \%)$. Отказ пациенток от лечения в связи с болевым синдромом в брюшной полости после введения наблюдался у 3-х больных. В 2-х случаях в связи с явлениями спаечной болезни было решено отказаться от в/б введений. Все эти пациентки получили оставшиеся курсы терапии в/в. У двух больных в связи с длительным периодом восстановления после оптимальной циторедукции решено начать 1-й курс терапии в/в, имплантация порт-систем производилась лапароскопически непосредственно перед вторым курсом терапии. 
Таблища 1.

Клинико-аналнестические характеристики больных раком яичников, получавиих внутрибрюшинную и стандартную внутривенную химиотерапию 1-йлинии

\begin{tabular}{|c|c|c|c|}
\hline Признак & Внутрибрюшинная XT & Стандартные режимы ХТ & p \\
\hline Число больных & 64 & 49 & \\
\hline Возраст, медиана (годы) & $53(26-78)$ & $55(31-73)$ & 0,46 \\
\hline $\begin{array}{l}\text { ECOG-статус до начала XT: } \\
-0-1 \\
-2-3 \\
\end{array}$ & $\begin{array}{c}59 / 64(92,2 \%) \\
5 / 64(7,8 \%) \\
\end{array}$ & $\begin{array}{c}\text { Оценен у 47: } \\
46 / 47(97,9 \%) \\
1 / 47(2,1 \%) \\
\end{array}$ & 0,45 \\
\hline $\begin{array}{l}\text { Стадия: } \\
\text { Ic-II } \\
\text { III-IV } \\
\end{array}$ & $\begin{array}{l}23 / 64(35,9 \%) \\
41 / 64(64,1 \%) \\
\end{array}$ & $\begin{array}{l}14 / 49(28,6 \%) \\
35 / 49(71,4 \%) \\
\end{array}$ & 0,53 \\
\hline $\begin{array}{l}\text { Гистологический тип } \\
\text { аденокарциномы: } \\
\text { серозная } \\
\text { другие }\end{array}$ & $\begin{array}{l}52 / 64(81,2 \%) \\
12 / 64(18,8 \%)\end{array}$ & $\begin{array}{l}38 / 49(77,5 \%) \\
11 / 49(22,5 \%)\end{array}$ & 0,80 \\
\hline $\begin{array}{l}\text { Степень злокачественности: } \\
\text { - высокая } \\
\text { - низкая }\end{array}$ & $\begin{array}{c}\text { Оценена у 61: } \\
53 / 61(86,8 \%) \\
8 / 61(13,2 \%) \\
\end{array}$ & $\begin{array}{c}\text { Оценена у 40: } \\
34 / 40(85 \%) \\
6 / 40(15 \%) \\
\end{array}$ & 0,78 \\
\hline Мутация BRCA1/2 & $\begin{array}{c}\text { Определен у 44: } \\
17 / 44(38,6 \%) \\
\end{array}$ & $\begin{array}{c}\text { Определен у 28: } \\
13 / 28(46,4 \%) \\
\end{array}$ & 0,68 \\
\hline $\begin{array}{l}\text { СА } 125 \text { перед хирургическим } \\
\text { лечением, медиана (Ед/мл) }\end{array}$ & $174(12,5-5180,0)$ & $219,7(8,19-5261,0)$ & 0,40 \\
\hline СА 125 перед ХТ, медиана (Ед/мл) & $67,7(9,0-1321,0)$ & $75,5(10-3189)$ & 0,92 \\
\hline $\begin{array}{l}\text { Размер остаточных очагов: } \\
\text { - микроскопические (0 см) } \\
\text { - до } 1 \text { см в диаметре }\end{array}$ & $\begin{array}{l}48 / 64(75,0 \%) \\
16 / 64(25,0 \%)\end{array}$ & $\begin{array}{l}38 / 49(77,5 \%) \\
11 / 49(22,5 \%)\end{array}$ & 0,92 \\
\hline
\end{tabular}

Токсичность внутрибрюшинной химиотерапии

Все виды токсичности могут быть разделены на 2 группы: 1) местную, связанную с порт-системой и в/б введениями и 2) системную, типичную для цитостатических агентов.

Осложнения, связанные с в/б порт-системой наблюдались у 18 из 64 больных (28,1\%). В таблице 2 подробно продемонстрированы местные осложнения, связанные с имплантируемой порт-системой. Самым частым осложнением был выход вводимых растворов в подкожную клетчатку. Первым в/б вводился физиологический раствор в объеме 500 мл, поэтому данный вид осложнений наблюдался на этом этапе, попадание подкожно цисплатина наблюдалось только у одной больной, данных за миолиз получено не было.

Почти все пациентки, принявшие участие в исследовании, испытывали системные побочные реакции. Основные виды токсичности представлены в таблице 3. Гематологическая токсичность в виде нейтропении 4 ст. развивалась у 40 (66,6\%) больных. Фебрильная нейтропения возникала однократно у 4-х (6,6\%) больных. Назначение Г-КСФ в связи с задержкой начала лечения и/или фебрильной нейтропении потребовалось в 5/75 (6,6\%) случаях. Анемия 3-4 ст. наблюдалась у 7 (11,6\%) больных. Гемотрансфузия эритроцитарной массы потребовалась 6 (8\%) пациенткам. Тромбоцитопения 2-3 ст. была редким осложнением и встречалась у двух больных. В одном случае возникла необходимость в трансфузии тромбоконцентрата. Среди негематологических видов токсичности стоит отметить диарею 3-4 ст. (11,7\% случаев), астению 3 ст. (19,6\%), нефротоксичность 1-2 ст. у 7-ми больных (13,7\%), что послужило необходимостью замены цисплатина на карбоплатин в 4-х случаях. Симптомы периферической полинейропатии возникали у 34 (57,6\%) пациенток, при этом нейропатии 3 ст. не было отмечено ни у одной больной. Во всех остальных случаях токсичность 3-4 ст. не превышала 4\%.

Одним из часто описываемых в литературе осложнений внутрибрюшинной терапии является болевой синдром в брюшной полости после введения цитостатиков. В нашем исследовании данный вид токсичности был прослежен у 56 больных. У 36 из 56 (64,3\%) отмечено появление болевого синдрома. Из них болевой синдром 1-2 ст. возникал у 27 из 36 пациенток (75\%) и у 9/36 (25\%) отмечался болевой синдром 3-4 ст. Обезболивание полунаркотическими анальгетикам (трамадол) требовалось 5-ти больным с болевым синдромом 3-4 ст. Отказ от лечения, обусловленный данным осложнением, наблюдался у 3 -х из 64 (4,6\%) пациенток после 3-его и 5-ого курсов химиотерапии. Однако стоит отметить, что чаще всего болевой синдром в брюшной полости проявлялся на первых курсах лечения. При анализе токсичности 
Таблища 2.

Местные осложнения, связанные с установленной порт-системой у больных раком яиников

\begin{tabular}{|l|c|}
\hline \multicolumn{1}{|c|}{ N больных с осложнениями, связанными с порт-системой } & $\mathbf{1 8 / 6 4 ~ ( 2 8 , 1 \% )}$ \\
\hline - Выход растворов в подкожную клетчатку: & $7 / 64(10,9 \%)$ \\
• Негерметичность порт-системы после интраперитонеальной установки & $4 / 64(6,3 \%)$ \\
- Фиброзирование катетера & $3 / 64(4,6 \%)$ \\
- Подтекание из резервуара порт-системы & $4 / 64(6,3 \%)$ \\
- Миграция резервуара порт-системы & $1 / 64(1,5 \%)$ \\
- Некорректное расположение дистального конца катетера & $3 / 64(4,6 \%)$ \\
- Спаечная кишечная непроходимость & $2 / 64(3,1 \%)$ \\
- Подозрение на инфицирование порт-системы & $2 / 64(3,1 \%)$ \\
\hline
\end{tabular}

Токсичность химиотерапии с использованием внутрибрюшинных введений

Таблица 3.

\begin{tabular}{|c|c|c|}
\hline Виды токсичности & \% от числа курсов ХT & \% от числа больных \\
\hline \multicolumn{3}{|c|}{ Гематологическая токсичность (оценена у 60 больных, N курсов ХТ 318) } \\
\hline $\begin{array}{l}\text { Нейтропения, все степени: } \\
-3-4 \text { ст. }\end{array}$ & $\begin{array}{l}202 / 318(63,5 \%) \\
92 / 318(28,9 \%)\end{array}$ & $\begin{array}{l}55 / 60(91,6 \%) \\
40 / 60(66,6 \%)\end{array}$ \\
\hline Фебрильная нейтропения & $4 / 318(1,2 \%)$ & $4 / 60(6,6 \%)$ \\
\hline $\begin{array}{l}\text { Тромбоцитопения } \\
-3-4 \text { ст. }\end{array}$ & $\begin{array}{l}3 / 318(0,9 \%) \\
2 / 318(0,6 \%) \\
\end{array}$ & $\begin{array}{l}2 / 60(3,3 \%) \\
1 / 60(1,6 \%) \\
\end{array}$ \\
\hline $\begin{array}{l}\text { Анемия, все степени: } \\
-3-4 \text { ст. }\end{array}$ & $\begin{array}{l}- \\
- \\
-\end{array}$ & $\begin{array}{c}40 / 60(66,6 \%) \\
7 / 60(11,6 \%) \\
\end{array}$ \\
\hline \multicolumn{3}{|c|}{ Негематологическая токсичность (оценена у 51 больной, N курсов ХT 271) } \\
\hline \multicolumn{3}{|c|}{ Гастро-интестинальная токсичность } \\
\hline $\begin{array}{l}\text { Тошнота, все степени: } \\
-3-4 \text { ст. }\end{array}$ & $\begin{array}{c}127 / 271(46,8 \%) \\
2 / 271(0,7 \%)\end{array}$ & $\begin{array}{c}33 / 51(64,7 \%) \\
2 / 51(3,9 \%)\end{array}$ \\
\hline $\begin{array}{l}\text { Рвота, все степени: } \\
-1-2 \text { ст. }\end{array}$ & $\begin{array}{l}40 / 271(14,7 \%) \\
40 / 271(14,7 \%)\end{array}$ & $\begin{array}{l}17 / 51(33,3 \%) \\
17 / 51(33,3 \%)\end{array}$ \\
\hline $\begin{array}{l}\text { Стоматит, все степени: } \\
-3-4 \text { ст. }\end{array}$ & $\begin{array}{c}11 / 271(4,0 \%) \\
1 / 271(0,3 \%)\end{array}$ & $\begin{array}{l}5 / 51(9,8 \%) \\
1 / 51(1,9 \%) \\
\end{array}$ \\
\hline $\begin{array}{l}\text { Диарея, все степени: } \\
-3-4 \text { ст. }\end{array}$ & $\begin{array}{l}18 / 271(6,6 \%) \\
8 / 271(2,9 \%)\end{array}$ & $\begin{array}{c}10 / 51(19,6 \%) \\
6 / 51(11,7 \%)\end{array}$ \\
\hline \multicolumn{3}{|c|}{ Нейротоксичность (оценена у 59 больных) } \\
\hline $\begin{array}{l}\text { Нейротоксичность, все степени: } \\
-1-2 \text { ст. }\end{array}$ & $\begin{array}{l}- \\
- \\
\end{array}$ & $\begin{array}{l}34 / 59(57,6 \%) \\
34 / 59(57,6 \%)\end{array}$ \\
\hline \multicolumn{3}{|c|}{ Метаболическая токсичность } \\
\hline Повышение трансаминаз & $2 / 271(0,7 \%)$ & $2 / 51(3,9 \%)$ \\
\hline Нефротоксичность 1-2 ст. & - & $7 / 51(13,7 \%)$ \\
\hline \multicolumn{3}{|c|}{ Другие виды токсичности } \\
\hline $\begin{array}{l}\text { Боли в брюшной полости*, все степени: } \\
-3-4 \text { ст. }\end{array}$ & $\begin{array}{c}107 / 295(36,2 \%) \\
19 / 295(6,4 \%) \\
\end{array}$ & $\begin{array}{l}36 / 56(64,3 \%) \\
9 / 56(16,1 \%) \\
\end{array}$ \\
\hline $\begin{array}{l}\text { Астения, все степени: } \\
-3 \text { ст. }\end{array}$ & $\begin{array}{l}- \\
- \\
\end{array}$ & $\begin{array}{l}43 / 51(84,3 \%) \\
10 / 51(19,6 \%)\end{array}$ \\
\hline $\begin{array}{l}\text { Артралгия, все степени: } \\
-3 \text { ст. }\end{array}$ & $\begin{array}{c}75 / 271(27,6 \%) \\
10 / 271(3,6 \%) \\
\end{array}$ & $\begin{array}{c}28 / 51(54,9 \%) \\
5 / 51(9,8 \%)\end{array}$ \\
\hline
\end{tabular}

* - болевой синдрам в брюшной полости оценен у 56 больных. 
в зависимости от числа курсов внутрибрюшинной терапии $(\mathrm{N}=295)$ болевой синдром наблюдался на 107 (36,2\%) курсах лечения. Из них токсичность 3-4 ст. отмечена на 19/107 (17,7\%) курсах терапии.

\section{Отдаленные результаты лечения больных}

На момент анализа все 64 пациентки закончили лечение. При медиане времени наблюдения 20,8 (4,7-81,7) месяцев прогрессирование заболевания выявлено у 19/64 (29,6\%) больных, умерли 4/64 $(6,2 \%)$ пациентки. После окончания ХТ прогрессирование заболевания не наблюдалось у всех больных. Медиана числа курсов в/б терапии равнялась 6 (1-6). Медиана уровня маркера СА125 после выполнения циторедукции составила 67,7 (9-1321) Ед/мл. Медиана уровня маркера СА125 после окончания лечения - 11,4 (1,54-33,0) Ед/мл. Нормализация маркера СА 125 происходила чаще всего после первого курса в/б химиотерапии.

Медиана ВБП составила 38,6 месяцев, 1-летняя БРВ - 87,4\%. Медиана Пж в настоящий момент составила 74,9 месяца. Медиана ВБП у больных с III-IV стадиями равнялась 23,1 месяца, 1 -летняя БРВ - 72,1\%. Прогрессирование в группе больных с III-IV стадиями заболевания и отсутствием макроскопических признаков болезни возникало значительно позже и составило 38,6 месяца по сравнению с 12,8 месяцами в группе больных с наличием остаточной опухоли до 1 см.

Сравнение эффективности внутрибрюшинной химиотерапии с историческим контролем у больных распространенным раком яичников

Мы провели сравнительный анализ результатов лечения с использованием в/б (проспективная группа) и стандартного в/в (ретроспективная группа) режимов химиотерапии 1-й линии. Проспективную группу составили 64 пациентки PЯ Ic-IV стадий, закончившие 1-ю линию в/б химиотерапии. В ретроспективную группу вошли больные РЯ Ic-IV стадий после оптимальной циторедукции на первом этапе и получившие 1-ю линию химиотерапии с использованием таксанов и препаратов платины каждые 3 недели в 2007-2016 годах. Исходя из критериев включения, в группу контроля вошли 49 пациенток. Основные клинико-анамнестические данные сравниваемых групп больных представлены в таблице 1. Обе изучаемые группы были сопоставимы по основным клиническим признакам.

Медиана ВБП у больных, получавших стандартное лечение, составила 29,5 месяцев, а в группе в/б химиотерапии - 38,6 месяцев, однако данные не имели статистической значимости $(\mathrm{p}=0,5)$ (рис. $1 \mathrm{~A})$. В связи с тем, что в большинстве исследований было получено преимущество в/б терапии по сравнению с системным лечением в подгруппе больных с поздними стадиями заболевания, нами был проведен анализ отдаленных результатов для распространенных стадий (III-IV). Оказалось, что различия составляют 7,5 месяцев, но не являются статистически значимыми: медиана ВБП в группе в/б химиотерапии составила 30,9 месяца и в группе стандартного лечения $23,4$ месяца ( $\mathrm{p}=0,37)$ (рис. 1Б).

Учитывая вероятность погрешности в определении размеров остаточной опухоли, мы перешли к третьему этапу анализа оценки ВБП у больных с полной циторедукцией. В группе в/б терапии таких больных оказалось 48, в группе системного в/в лечения - 39. Медиана ВБП оказалась значимо выше в группе больных, получавших в/б химиотерапию в сравнении с пациентками, которые получали стандартное в/в лечение: 38,6 месяцев и 26,9 месяцев соответ-

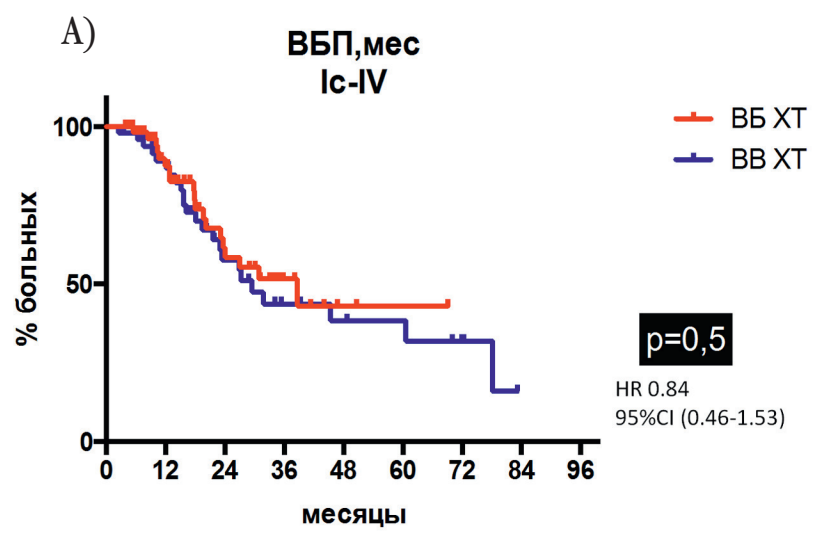

\begin{tabular}{|c|c|c|}
\hline ВБП, мес. & $\begin{array}{c}\text { BВ XT } \\
(\mathrm{N}=49)\end{array}$ & $\begin{array}{c}\text { ВБ XТ } \\
(\mathrm{N}=64)\end{array}$ \\
\hline Событие & $24 / 49(48,9 \%)$ & $20 / 64(38,6 \%)$ \\
\hline Iс-IV & 29,5 & 38,6 \\
\hline
\end{tabular}

Б)

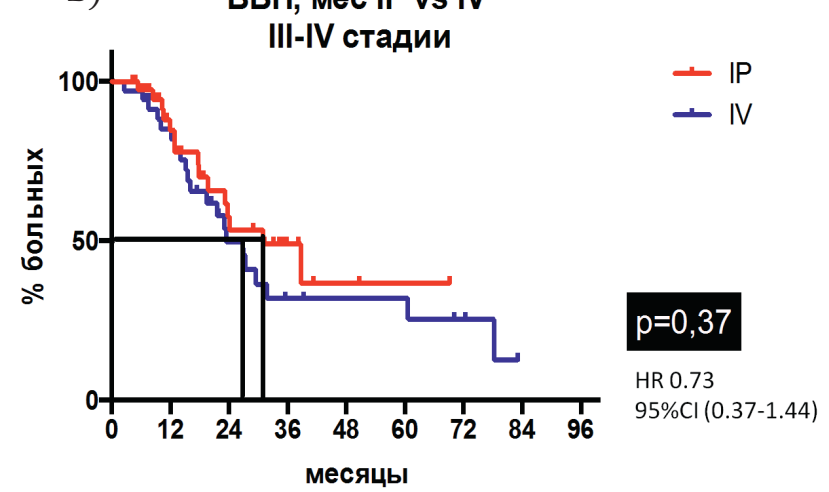

\begin{tabular}{|c|c|c|}
\hline ВБП, мес & $\begin{array}{c}\text { ВВ XT } \\
(\mathrm{N}=35)\end{array}$ & $\begin{array}{c}\text { ВБ XT } \\
(\mathrm{N}=41)\end{array}$ \\
\hline Событие & $21 / 35(60,0 \%)$ & $16 / 41(39,0 \%)$ \\
\hline Iс-IV & 23,4 & 30,9 \\
\hline
\end{tabular}

Рис. 1. Медианы ВБПу больных раком яичников Ic-IV и III-IV стадий, получавших стандартную и внутрибрюшинную химиотерапию: А) все больные; Б) больные с III-IV стадиями 
ственно (ОР 0,53; 95\% ДИ 0,27-0,96; $\mathrm{p}=0,05)$ (рис. 2A). Такая же тенденция сохраняется и у больных с III-IV стадиями заболевания. В данный поданализ вошли 52 больные с полной оптимальной циторедукцией: в группе контрольного лечения 24 пациентки, в группе в/б терапии 28 пациенток (рис. 2Б). Статистически значимое увеличение ВБП на 15,7 месяцев получено у больных PЯ III-IV стадий после оптимальной циторедукции без остаточной опухоли и проведения в $/ 6$ XT: медиана в группе в/б ХТ составила 38,6 месяца, в группе в/в ХТ - 22,9 месяца (ОР 0,60; 95\% ДИ 0,36-0,98; $\mathrm{p}=0,05)$.
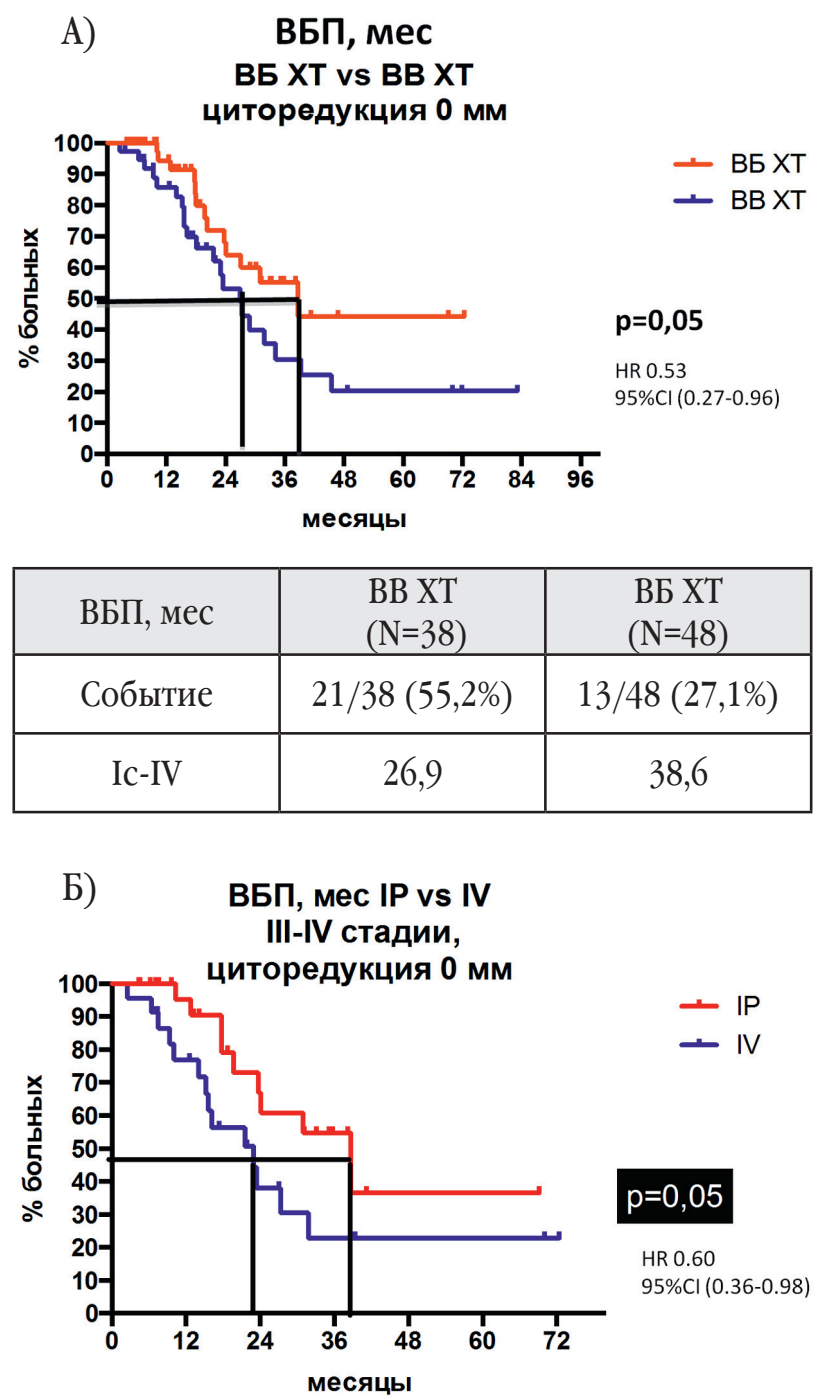

\begin{tabular}{|c|c|c|}
\hline ВБП, мес & $\begin{array}{c}\text { ВВ XТ } \\
(\mathrm{N}=24)\end{array}$ & $\begin{array}{c}\text { ВБ XT } \\
(\mathrm{N}=28)\end{array}$ \\
\hline Событие & $15 / 24(62,5 \%)$ & $10 / 28(35,7 \%)$ \\
\hline Iс-IV & 22,9 & 38,6 \\
\hline
\end{tabular}

Рис. 2. Время без прогрессирования у больных раком яичников после полной оптимальной циторедукции, получавших в/в и в/б ХT 1-й линии: A) Ic-IV стадии; Б) III-IV cтадuи
Для пациенток с остаточной опухолью 0-1 см различий в двух группах получено не было: медиана ВБП 26,8 месяца в группе системного лечения и 12,8 месяца в группе в/б терапии, $\mathrm{p}=0,46$. Столь низкие цифры медианы ВБП в группе в/б терапии у больных с резидуальной опухолью до 1 см могут быть обусловлены неадекватной ревизией после циторедуктивной операции, поскольку медиана ВБП, равная 12 месяцев, соответствует медиане ВБП после неоптимальных операций по данным отделения клинической фармакологии и химиотерапии [9]. Эта погрешность могла повлиять на общие отдаленные результаты лечения.

Отмечена тенденция к увеличению медианы ВБП у больных-носителей патогенной мутации генов BRCA1/2 (N=17), получающих в/б терапию по сравнению со стандартным лечением (N=13): медиана ВБП составляет 38,6 месяца и 21,5 месяца соответственно $(\mathrm{p}=0,1)$ (рис. 3$)$.

\section{BRCAmt: IP vs IV}

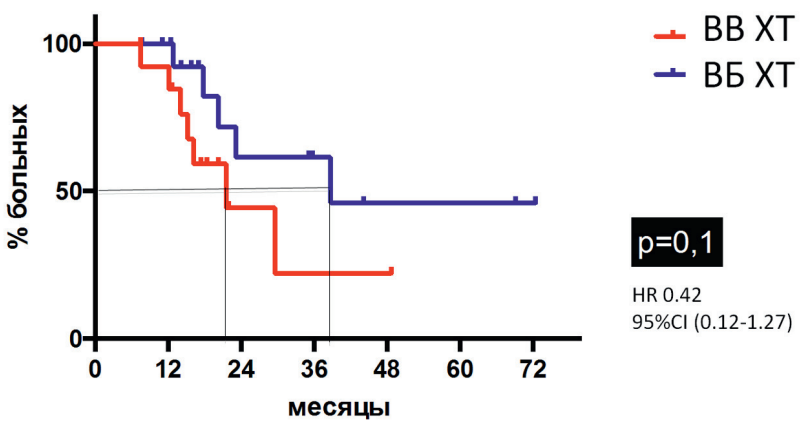

\begin{tabular}{|c|c|c|}
\hline Вид ХТ & ВВ ХТ & ВБ ХТ \\
\hline Событие & $7 / 13(53,8 \%)$ & $7 / 17(29,4 \%)$ \\
\hline $\begin{array}{c}\text { Медиана ВБП, } \\
\text { мес }\end{array}$ & 21,8 & 38,6 \\
\hline
\end{tabular}

Рис. 3. Время без прогрессирования у больных с мутациями в генах ВRCA1/2, получавиих в/в и в/б ХТ

\section{Дискуссия}

В/б терапия показала свою эффективность у больных с полной оптимальной циторедукцией как для всех стадий, так и для больных PЯ III-IV стадий. Токсичность, связанная в в/б введениями, возникала в $28,1 \%$ случаев, но была управляема, $79,7 \%$ больных смогли получить весь запланированный объем в/б введений. Системная гематологическая токсичность была сопоставима с данными литературы, что подтверждает достижение системной концентрации цитостатиков после в/б введений [6].

Полученные результаты демонстрируют, что в/б химиотерапия у больных распространенным РЯ эффективна, и не противоречат данным международных исследований, в которых в/б химиотерапия может быть рекомендована в первой линии лечения 
при минимальном остаточном проявлении болезни после первичной циторедукции. Результаты нашего исследования в очередной раз демонстрируют неэффективность данного метода у больных с крупными остаточными метастатическими очагами. Призываем еще раз обратить внимание на тот факт, что использование данной методики в рамках предоперационной химиотерапии или при массивной резидуальной опухоли не имеет преимуществ перед стандартным системным лечением.

Полученные нами данные $(28,1 \%)$ соответствуют частоте местной токсичности, оцененной в исследовании GOG172, где этот показатель составил 33\% [10]. Данный вид токсичности управляем, и ее частота возникновения может быть снижена в процессе приобретения большего опыта имплантации порт-систем. В нашей работе 79,7\% больных смогли закончить все запланированное лечение в/брюшинно. Для сравнения, в исследовании GOG172 только 42\% больных смогли получить 1-ю линию химиотерапии с в/б введениями в полном объеме [6]. В исследовании GOG252 эта цифра составила 84\% [7]. Можно предположить, что снижение дозы цисплатина до стандартной (со $100 \mathrm{мг} / \mathrm{M}^{2}$ до $75 \mathrm{mг} / \mathrm{M}^{2}$ ) позволяет значительно улучшить переносимость в/б химиотерапии и практически приблизиться к переносимости системного лечения (около 90\% больных в группе в/в терапии получают все 6 запланированных курсов лекарственного лечения). Системная токсичность соответствует данным литературы, а полученные результаты косвенно демонстрируют достижение достаточной концентрации цитостатиков в кровеносном русле, поскольку цифры гематологической токсичности у больных, получавших в/б химиотерапию соответствует таковым при в/в химиотерапии.

Внедрение в/б терапии в рутинную практику нашего центра оказалось довольно трудным процессом. Об этом свидетельствует активность набора больных в исследование. Первой причиной является низкое число оптимальных циторедукций у больных с распространенным РЯ. В отечественной литературе хирурги-онкогинекологи не публикуют свои собственные результаты. По данным отделения клинической фармакологии, частота первичных оптимальных циторедукций у больных с IIIc-IV стадией составляет всего 33,5\% [9]. Второй причиной могут являться парамедицинские трудности - например, отсутствие времени у хирурга для имплантации порт-системы, хотя длительность данной манипуляции составляет 15-20 мин. В связи с этим будет сохраняться барьер для внедрения в рутинную практику имплантации в/б порт-систем во время операции. По этой причине совместно с отделением эндоскопии нами был разработан метод лапароскопической имплантации в/б порта. Преимуществом метода является возможность повторной оценки оптимальности циторедукции и выявление противопоказаний к установке порт- системы, например, спаечного процесса в брюшной полости. В тоже время эта процедура становится дорогостоящей, поскольку включает необходимость проведения системной анестезии, и увеличивает риски осложнений после данной манипуляции.

Третьей и самой сложной проблемой оказалась оценка остаточной опухоли после операции. При планировании сравнительного анализа отдаленных результатов в группах в/б и в/в терапии нами был проведен анализ в подгруппах больных только с полной оптимальной циторедукцией $(0$ cм), поскольку мы предполагали, что погрешность в оценке остаточных проявлений у пациенток с резидуальной опухолью 0-1 см может повлиять на отдаленные результаты. у больных без макроскопических признаков болезни было получено значимое преимущество на 11,7 месяцев в группе в/б химиотерапии по сравнению с группой в/в лечения. Эти данные не противоречат мировой литературе, в исследовании GOG114 преимущество в медиане ВБП у больных в группе в/б химиотерапии составило 6 месяцев, в исследовании GOG172 - 12 месяцев [5, 6]. В то время как у больных с остаточной опухолью $0-1$ см различия не были получены. Медиана ВБП в этой группе больных была значительно ниже и составила 12,8 месяца. Оказалось, что эти цифры сопоставимы с медианой ВБП у 88 больных с первичной неоптимальной циторедукцией (остаточная опухоль более 1 см), получавших 1-ю линию системной химиотерапии в отделении клинической фармакологии, где эта цифра составила 11,5 месяца [9]. Такие результаты позволяют усомниться в корректности оценки оптимальности циторедукции, и мы предположили, что в/б порт-системы могли быть имплантированы больным после неоптимальных операций. Для того, чтобы проверить свою гипотезу, нами был проведен анализ по аналогии с исследованием клиники MSKCC [11]. В данной работе были отобраны больные с IIIc стадией РЯ, которым была выполнена первичная циторедукция на первом этапе. В дальнейшем они получали платино-содержащую химиотерапию. У всех этих пациенток был измерен уровень маркера СА125 перед операцией и его значение превышало 35 Ед/мл, второе измерение было сделано перед началом химиотерапии 1-й линии. Разница между двумя значениями СА125 высчитывалась в процентах. Оказалось, что медиана снижения маркера СА125 у больных после оптимальной циторедукции составила 73\% (от увеличения на 324\% до снижения на 99\%), а в группе неоптимальных циторедукций данный показатель был значительно ниже - 55\% (от увеличения на $112 \%$ до снижения на 99\%, p $<0,001$ ). Мы провели аналогичный поданализ у наших больных, вошедших в исследование. Из 113 больных, получавших в/в и в/б ХТ после первичной оптимальной циторедуктивной операции, в 40 случаях у пациенток с IIIc-IV стадиями определялось повышенное значение маркера СА 125 более 35 Ед/мл. Также мы включили 
Таблища 5.

Снижение маркера СА125 после операщии в зависимости от объема цитторедукции для IIIc-IV стадий

\begin{tabular}{|l|c|c|c|c|}
\hline \multicolumn{1}{|c|}{ Исследование } & $\begin{array}{c}\mathbf{N} \\
\text { больных }\end{array}$ & $\begin{array}{c}\text { Размер остаточной } \\
\text { опухоли }\end{array}$ & $\begin{array}{c}\text { Медиана снижения } \\
\text { СА125, \% }\end{array}$ & $\mathbf{p}$ \\
\hline Zivanovic О 2009 [11] & 307 & $0-1$ см & $73 \%(-324 \%-+99 \%)$ & 0,0001 \\
& $>1$ см & $55 \%(-112 \%-+99 \%)$ & \\
\hline НМИЦ онкологии & \multirow{2}{*}{128} & 0 см & $77,9 \%(-183 \%-+98 \%)$ & $0,003^{*}$ \\
Н.Н. Блохина & $>1$ см & $59,5 \%(-1395 \%-+94 \%)$ & \\
\hline
\end{tabular}

* р рассчитано для сравнения группы 0 см и совмещенных групп 0-1 и>1 см.

в анализ 88 пациенток, получавших в/в ХТ по поводу первичной неоптимальной циторедукции и имевших повышенный уровень маркера СА125 до хирургического этапа лечения. Оказалось, что медиана разницы маркера СА125 до и после операции у больных без остаточной опухоли составила $77,9 \%$ (от увеличения на 183\% до снижения на 98\%). В группе больных с остаточной опухолью $0-1$ см данный показатель был значительно ниже и соответствовал показателю у больных с неоптимальными циторедукциями: для больных с резидуальной опухолью $0-1$ см - 59,5\% (от увеличения на 1395\% до снижения на 94\%), для больных с неоптимальной циторедукцией - $58,2 \%$ ((от увеличения на 21272\% до снижения на 96,4\%), различия статистически значимы $\mathrm{p}=0,003)$ (табл. 5). Полученные нами данные соответствуют результатам клиники MSKСС. Таким образом, мы можем косвенно подтвердить, что пациентки с остаточной опухолью 0-1 см и вошедшие в исследование по в/б химиотерапии были прооперированы в неоптимальном объеме, что повлияло на отсутствие статистически значимых различий в медиане ВБП у всех больных, принявших участие в исследовании, в сравнении со стандартным в/в лечением.

Таким образом, проблема оценки оптимальности циторедуктивной операции и правильного оформления протокола хирургического вмешательства остается актуальной до сих пор и становится особенно значимой в связи с тем, что пациентки с оптимальной циторедукцией требуют более агрессивного лекарственного лечения с использованием в/б введений. Нами был разработан протокол операции с подробной оценкой остаточной опухоли, который находится в свободном доступе и был предложен коллегам для апробации (https: //rosoncoweb.ru > library > 2006/05 > protocol). Данная форма позволяет четко отследить все необходимые процедуры стадирования, объем хирургического вмешательства и оценить расположение и объем резидуальных очагов, что позволяет в последующем отслеживать динамику на фоне цитостатического лечения. Внедрение стандартизованного протокола в рутинную клиническую практику позволит эффективнее оценивать качество хирургического лечения и корректно подойти к выбору химиотерапии.

\section{Заключение}

В/б химиотерапия позволяет улучшить результаты лечения больных с минимальными проявлениями заболевания после первичного циторедуктивного вмешательства и может быть рекомендована в качестве основного лечения у этой группы больных. Создается впечатление, что пациентки с наследственным РЯ выигрывают от данного вида лечения по сравнению со стандартной терапией. Внедрение стандартизованного протокола хирургического лечения позволит улучшить качество оценки остаточной опухоли и рационально подобрать дальнейшее лечение. Внедрение в/б химиотерапии требует работы мультидисциплинарной команды, состоящей из хирургов, химиотерапевтов, специалистов по эндоскопии, что позволит значительно повысить качество оказания помощи больным распространенным РЯ.

\section{Список литературы}

1. Тюляндин С.А., Коломиеи,Л.А., Морхов К.Ю. и др. Практические рекомендации по лекарственному лечению рака яичников, первичного рака брюшины и рака маточной трубы // Злокачественные опухоли. - 2018. T. 8. - C. 145-155.

2. Alberts D.S., Surwit E.A., Peng Y.M. et al. Phase I clinical and pharmacokinetic study of mitoxantrone given to patients by intraperitoneal administration // Cancer Res. - 1988. - Vol. 48. - P. 5874-5877.

3. Fujiwara K., Armstrong D., Morgan M. et al. Principles and practice of intraperitoneal chemotherapy for ovarian cancer // Int. J. Gynecol. Cancer. - 2007. - Vol. 17. - P. 1-20. 
4. Alberts D.S., Liu P.Y., Hannigan E.V. et al. Intraperitoneal cisplatin plus intravenous cyclophosphamide versus intravenous cisplatin plus intravenous cyclophosphamide for stage III ovarian cancer // J. Clin. Oncol. - 1996. Vol. 14. - P. 2113-2119.

5. Markman M., Bundy B.N., Albetrs D.S. et al. Phase III trial of standard-dose intravenous cisplatin plus paclitaxel versus moderately high-dose carboplatin followed by intravenous paclitaxel and intraperitoneal cisplatin in smallvolume stage III ovarian carcinoma; an intergroup study of the Gynecologic Oncology Group, Southwestern Oncology Group, and Eastern Cooperative Oncology Group // J. Clin. Oncol. - 2001. - Vol. 19. - P. 1001-1007.

6.Armstrong D.K., Bundy B., Wenzel L. et al. Gynecologic Oncology Group. Intraperitoneal cisplatin and paclitaxel in ovarian cancer // N. Engl. J. Med. - 2006. - Vol. 354. - P. 34-43.

7. Walker J.L., Brandy M.F., Wenzel L. et al. Randomized trial of intravenous versus intraperitoneal chemotherapy plus bevacizumab in advanced ovarian carcinoma: an NRG oncology/ gynecologic oncology group study // J Clin. Oncol. - 2019. - Vol. 37. - № 16. - P. 1380-1390.

8.Тюляндина А.С. Интенсивные режимы химиотерапии первой линии при распространенном раке яичников: дис. ... канд. мед. наук: 14.01.12 / Тюляндина Александра Сергеевна. - М., 2012. - 139 с.

9. Тюляндина А.С., Румянщев А.А., Нечушкина В.M. и др. Ретроспективный анализ отдаленных результатов применения первичной циторедукци и предоперационной химиотерапии на первом этапе лечения больных IIIc-IV стадий рака яичников // Злокачественные опухоли. - 2018. - Т. 8. - С. 87-94.

10. Walker J.L., Armstrong D.K., Huang H.Q. et al. Intraperitoneal catheter outcomes in a place III trial of intravenous versus intraperitoneal chemotherapy in optimal stage ovarian cancer: a Gynecologic Oncology Group Study // Gynecol. Oncol. - 2006. - Vol. 100. - P. 27-32.

11. Zivanovic O., Sima C.S., Iasonos A. et al. Exploratory analysis of serum CA125 response to surgery and the risk of relapse in patients with FIGO stage IIIC ovarian cancer // Gynecol. Oncol. - 2009. - Vol. 115. - P. 209-214.

\section{References}

1. Tyulyandin S.A., Kolomiets L.A., Morkhov K.Y. et al. Practical recommendations for the treatment of ovarian/ tube/ peritoneum cancer. Malignant tumors. 2018; 8: 145-155. (In Russ). doi: 10.18027 / 2224-5057-2018-8-3s2-145-155.

2. Alberts D.S., Surwit E.A., Peng Y.M. et al. Phase I clinical and pharmacokinetic study of mitoxantrone given to patients by intraperitoneal administration. Cancer Res. 1988; 48: 5874-5877.

3. Fujiwara K., Armstrong D., Morgan M. et al. Principles and practice of intraperitoneal chemotherapy for ovarian cancer. Int J Gynecol Cancer. 2007; 17: 1-20.

4. Alberts D.S., Liu P.Y., Hannigan E.V. et al. Intraperitoneal cisplatin plus intravenous cyclophosphamide versus intravenous cisplatin plus intravenous cyclophosphamide for stage III ovarian cancer. J Clin Oncol. 1996; 14: 2113-2119.

5. Markman M., Bundy B.N., Albetrs D.S. et al. Phase III trial of standard-dose intravenous cisplatin plus paclitaxel versus moderately high-dose carboplatin followed by intravenous paclitaxel and intraperitoneal cisplatin in smallvolume stage III ovarian carcinoma; an intergroup study of the Gynecologic Oncology Group, Southwestern Oncology Group, and Eastern Cooperative Oncology Group. J Clin Oncol. 2001; 19: 1001-1007.

6.Armstrong D.K., Bundy B., Wenzel L. et al. Gynecologic Oncology Group. Intraperitoneal cisplatin and paclitaxel in ovarian cancer. N Engl J Med. 2006; 354: 34-43.

7. Walker J.L., Brandy M.F., Wenzel L. et al. Randomized trial of intravenous versus intraperitoneal chemotherapy plus bevacizumab in advanced ovarian carcinoma: an NRG oncology/gynecologic oncology group study. J Clin Oncol. 2019; 37(16): 1380-1390.

8. Tyulyandina A.S. Intensive first line chemotherapy regimens in patients with advanced ovarian cancer. 2012; 139. (In Russ)

9. Tyulyandina A.S., Nechushkina V.M., Rumyantsev A.A. et al. Retrospective analysis of long-term survival outcomes of primary cytoreduction and neoadjuvant chemotherapy in patients with ovarian cancer stage IIIc-IV. Malignant tumors. 2018; 3: 86-94. (In Russ)

10. WalkerJ.L., Armstrong D.K., Huang H.Q. et al. Intraperitoneal catheter outcomes in a place III trial of intravenous versus intraperitoneal chemotherapy in optimal stage ovarian cancer: a Gynecologic Oncology Group Study. Gynecol Oncol. 2006; 100: 27-32.

11.Zivanovic O., Sima C.S., Iasonos A. et al. Exploratory analysis of serum CA125 response to surgery and the risk of relapse in patients with FIGO stage IIIC ovarian cancer. Gynecol Oncol. 2009; 115(2); 209-214. 